\title{
Unravelling mummies: cryptic diversity, host specificity, trophic and coevolutionary interactions in psyllid - parasitoid food webs
}

Aidan A. G. Hall' ${ }^{1}$ Martin J. Steinbauer², Gary S. Taylor ${ }^{3}$, Scott N. Johnson', James M. Cook ${ }^{1}$ and Markus Riegler ${ }^{{ }^{*}}$

\begin{abstract}
Background: Parasitoids are hyperdiverse and can contain morphologically and functionally cryptic species, making them challenging to study. Parasitoid speciation can arise from specialisation on niches or diverging hosts. However, which process dominates is unclear because cospeciation across multiple parasitoid and host species has rarely been tested. Host specificity and trophic interactions of the parasitoids of psyllids (Hemiptera) remain mostly unknown, but these factors are fundamentally important for understanding of species diversity, and have important applied implications for biological control.
\end{abstract}

Results: We sampled diverse parasitoid communities from eight Eucalyptus-feeding psyllid species in the genera Cardiaspina and Spondyliaspis, and characterised their phylogenetic and trophic relationships using a novel approach that forensically linked emerging parasitoids with the presence of their DNA in post-emergence insect mummies. We also tested whether parasitoids have cospeciated with their psyllid hosts. The parasitoid communities included three Psyllaephagus morphospecies (two primary and, unexpectedly, one heteronomous hyperparasitoid that uses different host species for male and female development), and the hyperparasitoid, Coccidoctonus psyllae. However, the number of genetically delimited Psyllaephagus species was three times higher than the number of recognisable morphospecies, while the hyperparasitoid formed a single generalist species. In spite of this, cophylogenetic analysis revealed unprecedented codivergence of this hyperparasitoid with its primary parasitoid host, suggesting that this single hyperparasitoid species is possibly diverging into host-specific species. Overall, parasitoid and hyperparasitoid diversification was characterised by functional conservation of morphospecies, high host specificity and some host switching between sympatric psyllid hosts.

Conclusions: We conclude that host specialisation, host codivergence and host switching are important factors driving the species diversity of endoparasitoid communities of specialist host herbivores. Specialisation in parasitoids can also result in heteronomous life histories that may be more common than appreciated. A host generalist strategy may be rare in endoparasitoids of specialist herbivores despite the high conservation of morphology and trophic roles, and endoparasitoid species richness is likely to be much higher than previously estimated. This also implies that the success of biological control requires detailed investigation to enable accurate identification of parasitoid-host interactions before candidate parasitoid species are selected as biological control agents for target pests.

Keywords: Coevolution, Conserved trophic roles, Cryptic species, Diversification, Heteronomous hyperparasitoid, Parasitoid

\footnotetext{
* Correspondence: m.riegler@westernsydney.edu.au

'Hawkesbury Institute for the Environment, Western Sydney University,

Locked Bag 1797, Penrith, NSW 2751, Australia

Full list of author information is available at the end of the article
}

(c) The Author(s). 2017 Open Access This article is distributed under the terms of the Creative Commons Attribution 4.0 International License (http://creativecommons.org/licenses/by/4.0/), which permits unrestricted use, distribution, and reproduction in any medium, provided you give appropriate credit to the original author(s) and the source, provide a link to the Creative Commons license, and indicate if changes were made. The Creative Commons Public Domain Dedication waiver (http://creativecommons.org/publicdomain/zero/1.0/) applies to the data made available in this article, unless otherwise stated. 


\section{Background}

Most insects suffer attack by parasitoids that can influence host population dynamics [1]. Parasitoids are hyperdiverse in their membership to different trophic levels (e.g. primary parasitoids or hyperparasitoids) and in species richness. In fact, it is estimated that hymenopteran parasitoids alone make up more than $20 \%$ of the world's insect species, yet only about $1 \%$ of all parasitoid species have been described $[1,2]$.

The predominant drivers of parasitoid diversification are niche and host specificity [3-6]. In niche specific parasitism, hosts that share ecological niches such as location, feeding niche or host plant, may share very similar parasitoid communities [7]. In contrast, host specific parasitism relates to parasitoids having a single host species or host species that are phylogenetically closely related with each other [8]. Assessing parasitoid diversification can be a difficult task as it requires knowledge of the species identity and ecology of both the host and parasitoid across multiple systems [9].

Cophylogenetic analysis can provide insights into speciation and diversification if the ecology of the host species and their respective parasitoids is known. However, very few studies have tested for codivergence between insect hosts and their parasitoids (but see [10-14]), and we are aware of none that have investigated cophylogenetic relationships between hosts, primary parasitoids and their hyperparasitoids. Given that hyperparasitoids can be host specific to either the host herbivore (e.g. [15]) or the primary parasitoid (e.g. [16]), such coevolutionary relationships can be predicted, and cophylogenetic analyses should provide further insight into this.

Studying host - parasitoid food webs can be very challenging due to the undescribed diversity of parasitoids [17]. DNA barcoding and molecular approaches have greatly improved sensitivity and accuracy in species identification and food web studies [18-20]. For example, DNA barcoding has sometimes demonstrated that parasitoid species thought to be generalists are in fact host specific cryptic species, and hence parasitoid species richness is likely to be far higher than currently estimated [21, 22].

Eucalyptus-feeding psyllids, native to Australia, are highly diverse and host specific, with host ranges of either a single or several Eucalyptus species [23]. They can cause significant damage to trees during heavy infestations [24], and have become serious invasive pests of Eucalyptus plantations overseas [25-27]. The principal natural enemies of psyllids are chalcidoid parasitoids (Hymenoptera), including species from the families Aphelinidae, Encyrtidae, Eulophidae and Pteromalidae [28]. Of particular significance are species belonging to the encyrtid genus Psyllaephagus Ashmead. This genus includes morphologically difficult to distinguish species, and both primary parasitoids and hyperparasitoids have been described [28]. So far, around 110 Psyllaephagus species are known in Australia [29]; however, it is estimated that the actual diversity in Australia might be as high as 1000 species [30]. The dearth of knowledge about host specificity and trophic roles of Psyllaephagus spp. hinders assessment of their capacity to regulate psyllid abundance [31], and the implementation of biological control programs against invasive psyllids [32, 33]. Psyllaephagus species are solitary koinobiont endoparasitoids [29], that is they feed inside still developing hosts before eventually killing them with the emergence of only one parasitoid from a parasitised host. It is expected that koinobiont endoparasitoids generally have greater host specificity because the parasitoids are constrained by their intimate physiological relationship with their hosts [7].

Cardiaspina Crawford (Hemiptera: Aphalaridae) includes the most damaging of Eucalyptus-feeding psyllids [24, 34]. Serious outbreaks of several Cardiaspina species have occurred in mainland Australia [35-39]. Furthermore, Cardiaspina fiscella has spread to New Zealand [40] and Norfolk Island [41]. Previous research of parasitoids and hyperparasitoids attacking Cardiaspina psyllids leads to two contrasting yet untested hypotheses. There are either (1) several morphologically distinct parasitoid species with a broader psyllid host range on Eucalyptus, suggesting niche specific parasitism, or, conversely (2) highly host specific parasitisation with different sets of parasitoid species for each Cardiaspina species. Given that Cardiaspina psyllids are known Eucalyptus specialists that have diversified only on this host plant genus [23], it is possible to hypothesise further that parasitoid communities associated with Cardiaspina have either cospeciated with diverging psyllid host lineages specialised to different Eucalyptus, or, alternatively, codifferentiated with psyllid species, i.e. with diverging psyllid host lineages providing new colonisation opportunities for different sets of parasitoid species.

We aimed to investigate the relative contribution of cospeciation and host switching to parasitoid community composition across several psyllid species that are closely and more distantly related to each other. Therefore, we examined parasitoid communities of psyllid species with similar ecological niches on different Eucalyptus species with partially overlapping geographic distributions. More specifically, we sampled parasitoid communities associated with seven species of Cardiaspina and one species of the closely related genus Spondyliaspis from different species of Eucalyptus across a wide geographic range in south eastern Australia. Given the limited ecological and taxonomic information available for this host - parasitoid system, we combined DNA characterisation of emerging parasitoid wasps and morphospecies-specific multiplex PCR on post-emergence 
mummies (parasitised psyllid nymphs) as a forensic DNAbased profiling approach to characterise parasitoid diversity, host specificity and trophic roles across several related psyllid species for the first time. We then performed multilocus cophylogenetic analyses to test for codivergence and host switches between hosts and their parasitoids. We hypothesised that some koinobiont endoparasitoid and hyperparasitoid species codiverge with their host species, and therefore, we predicted higher parasitoid than psyllid diversity, and higher parasitoid host specificity than anticipated from current knowledge about morphological diversity of this parasitoid genus. We also expected that parasitoid communities may be impacted by the process of codifferentiation with some parasitoids shifting host preference as a consequence of the mosaic distribution of Eucalyptus species (e.g. [42]). Furthermore, we predicted that, based on expected cryptic diversity, a more generalist strategy of parasitism in parasitoids would be rare for parasitoids of specialist herbivores, even between phylogenetically closely related host psyllids that occupy highly similar ecological niches. We also predicted that our DNA-based profiling approach of parasitoid interactions would reveal new life history strategies in diverse parasitoid communities as a consequence of host specialisation and competition.

\section{Methods}

\section{Field sampling and identification of parasitoid}

\section{morphotypes}

Parasitoids were collected from populations of seven Cardiaspina species and one population of a Spondyliaspis species from sites in Sydney, New South Wales (NSW), in Canberra, Australian Capital Territory (ACT) and Keith south east of Adelaide, South Australia (SA) (Additional file 1: Table S1). According to adult and lerp (protective covers excreted by nymphs) morphology, host tree association and DNA characterisation, Cardiaspina populations were assigned to six species (C. albitextura Taylor, C. densitexta Taylor, C. fiscella Taylor, C. maniformis Taylor, C. tenuitela Taylor and C. vittaformis Froggatt) that represent a phylogenetically broad diversity [43] of 24 known species of the genus Cardiaspina [23]. Cardiaspina from Eucalyptus moluccana Roxb. (Grey Box) was not assigned to any described species due to its recently described Eucalyptus association (GB Cardiaspina sp.) and uncertain species status [35]. First morphological identification placed it near C. densitexta [34] but molecular evidence did not unequivocally support this and clustered this species with both $C$. densitexta and $C$. tenuitela, two species feeding on other box eucalypts [43]. For the Spondyliaspis sp. and five of the seven Cardiaspina species, host plant leaves infested with psyllids were collected from trees within arm's reach from the ground and placed into zip-lock bags. Leaf collections were performed when psyllid nymphs were between third and fifth instar. The zip-lock bags containing the leaves were monitored daily for the development of mummies, which were then placed into individual gelatine capsules. Following emergence, parasitoids and post-emergence mummies were separated into tubes containing absolute ethanol for subsequent analysis. For the remaining two Cardiaspina species, $C$. densitexta and $C$. vittaformis, we did not obtain sufficient numbers of mummies to be placed into gelatine capsules, and therefore only adult parasitoid wasps were collected from zip-lock bags with infested leaves. Adult parasitoids were grouped into morphologically distinct morphotypes with males and females forming different morphotypes. Sex was determined based on ovipositor and antennal morphology [28, 44]. Later, sexes were grouped into morphospecies based on their molecular identity, and for some morphospecies only females were found. The translucent versus opaque (black) appearance of mummies was also informative for species differentiation. The previous assessment of the GB Cardiaspina sp. parasitoid community [35] revealed seven morphotypes (i.e. four female and three male morphotypes) that likely represented four morphospecies, three of which were sexually dimorphic and one that appeared to be only female. The parasitoid morphotypes from GB Cardiaspina sp. and C. fiscella were also confirmed by John La Salle and vouchered with the Australian National Insect Collection (CSIRO, Canberra) (Additional file 1: Table S2).

\section{DNA characterisation of parasitoid morphospecies}

Parasitoids were assigned to eight morphotypes (four female and four male morphotypes) which were later grouped into four major morphospecies by matching DNA sequences of female and male morphotypes - two primary parasitoid (P1 and P2), one hyperparasitoid (H) and one heteronomous hyperparasitoid (HH) (i.e. female $\mathrm{HH}$ developed from parasitised psyllids while male $\mathrm{HH}$ emerged from parasitised P1), as well as one rare aphelinid morphospecies. Where possible, four adult wasp specimens per morphospecies from each psyllid species were DNA profiled. For morphotypes for which only few individuals were obtained, DNA was extracted nondestructively following the protocol described in King et al. [45], while for the other morphotypes DNA was extracted after tissue homogenisation. DNA characterisation was performed with mitochondrial cytochrome $\mathrm{b}$ (cytb) [CB1 and CB2; 46], and the D2 expansion segment of nuclear 28S rDNA (D2-3551 F and D2-4057 R; [46]). The reaction mix for both loci comprised $1 \times$ GoTaq PCR buffer, 0.5 U GoTaq DNA polymerase (Promega, Madison, WI, USA), $3 \mathrm{mM} \mathrm{MgCl}_{2}, 0.1 \mathrm{mM}$ of each dNTP, $0.5 \mu \mathrm{M}$ of each primer and $2 \mu \mathrm{L}$ DNA template in a $20 \mu \mathrm{L}$ reaction volume. The PCR conditions for cytb were $94{ }^{\circ} \mathrm{C}$ for $3 \mathrm{~min}, 30$ cycles of $95{ }^{\circ} \mathrm{C}$ for $15 \mathrm{~s}, 45{ }^{\circ} \mathrm{C}$ for $20 \mathrm{~s}$ and $72{ }^{\circ} \mathrm{C}$ for $30 \mathrm{~s}$, with a final 
extension for $10 \mathrm{~min}$ at $72{ }^{\circ} \mathrm{C}$, and for $28 \mathrm{~S}$ rDNA the PCR conditions were $94{ }^{\circ} \mathrm{C}$ for $3 \mathrm{~min}, 30$ cycles of $94{ }^{\circ} \mathrm{C}$ for $45 \mathrm{~s}, 55{ }^{\circ} \mathrm{C}$ for $30 \mathrm{~s}$ and $72{ }^{\circ} \mathrm{C}$ for $90 \mathrm{~s}$, with a final extension for $10 \mathrm{~min}$ at $72{ }^{\circ} \mathrm{C}$ using a BioRad DNA engine Dyad, ${ }^{\circ}$ Peltier Thermal Cycler (CA, USA). PCR amplicons were sequenced by Macrogen (Korea), and DNA sequences were edited in Sequencher 4.10.1 (Gene Codes Corporation, Ann Arbor, MI, USA) and deposited in GenBank (Additional file 1: Table S3).

\section{Phylogenetic analysis and species delimitation}

A phylogeny of the parasitoid morphospecies from each psyllid population was constructed based on concatenated $c y t b$ and $28 \mathrm{~S}$ rDNA sequences. Sequence alignments were performed in Clustal X 2.1 [47]. Evolutionary models were selected for the two gene datasets separately using Bayesian Information Criterion in MEGA 6.06 [48]; HKY + G for $c y t b$ and T92 + G for $28 \mathrm{~S}$ rDNA. Phylogenetic relationships were estimated for gene and concatenated trees (with highly similar topologies) using Bayesian inference implemented in MrBayes 3.2.2 [49]. Posterior probabilities were calculated using four independent chains, including one cold, for 5 million generations, sampling every 100 generations, or until convergence was reached $(<0.01)$. The first $25 \%$ of trees generated were discarded and a 50\% majority rule consensus tree was returned. FigTree 1.4.0 [50] was used to view the trees. Putative species boundaries were found for the gene trees of both loci using the BPTP web server [51] and the default parameters. Sequence divergence for both loci was calculated using the p-distance analysis in MEGA.

A psyllid host phylogeny was constructed from concatenated sequence data of mitochondrial genes COI (506 bp) [52] and cytb (398 bp) [53], and nuclear genes $w g$ (268 bp), EF-1 alpha (281 bp) and CAD (323 bp) designed for this study (Additional file 1: Tables S4 and S5). Also included was COI sequenced from three Spondyliaspis sp. individuals (KT388061). Some gene sequences were not obtained for Spondyliaspis sp. and they were therefore coded as missing data in MrBayes 3.2.2. The psyllid gene tree topologies were highly similar and the concatenated tree provided greater resolution and was therefore deemed best for further analyses [54]. Putative species boundaries were found for the concatenated psyllid phylogeny using the bPTP web server.

\section{Identification of trophic interactions}

A morphospecies-specific multiplex PCR on postemergence mummies was used to examine trophic interactions. This involved the DNA sequence analysis of emerging parasitoids, the design of morphospeciesspecific primers and morphospecies-specific PCR testing of post-emergence mummies. If DNA of the psyllid host and only the emerging parasitoid species was consistently detected in post-emergence mummies then this was indicative that the emerging parasitoid was a primary parasitoid. If DNA of the host and two parasitoid species was consistently present in post-emergence mummies, and the DNA of the emerged parasitoid species was not detected alone in any mummy (i.e. without the presence of any other parasitoid species found in this experiment), then the emerged species was determined to be a hyperparasitoid of the primary parasitoid species that did not emerge.

Morphospecies-specific primers were designed based on morphospecies alignments of cytb sequences using SP-Designer v7.0 [55]. Sequences of P1 and HH from C. albitextura and $C$. tenuitela were too different to P1 and $\mathrm{HH}$ from the other host species. Therefore their specific primers had to be designed from separate alignments. Parameters were set for each primer pair to give a minimum of two diagnostic sites within the last five nucleotide positions at the $3^{\prime}$ end of each primer, different amplicon lengths (145-400 bp) and similar annealing temperatures to allow for multiplexing (Additional file 1: Table S6). Amplicon sizes for the primers of $\mathrm{P} 1$ and $\mathrm{HH}$ from $C$. albitextura and $C$. tenuitela were not different enough to differentiate them from $\mathrm{P} 2$ and $\mathrm{H}$. Therefore, for parasitoids of these two host species, the multiplex PCR had to be performed in two stages; one multiplex PCR for P1 and $\mathrm{HH}$, and another for P2 and H. Morphospecies-specificity and ability of the primers to co-amplify in different template DNA combinations were confirmed by both single and multiplex PCR using adult wasp and psyllid DNA. DNA sequencing of PCR products confirmed that they were not artefacts.

DNA from mummies was extracted using the Gentra Puregene Tissue Kit (Qiagen, Germany) following the manufacturer's instructions. Mummy extracts were deemed informative if DNA of both the emerging parasitoid and psyllid were detected by PCR. Psyllid DNA was amplified with primers for $w g$. For each parasitoid morphospecies and sex from each host population, two to 20 informative mummies were subjected to multiplex PCR in a $10 \mu \mathrm{L}$ reaction comprising $1 \times$ Qiagen Multiplex PCR Master Mix, $0.2 \mu \mathrm{M}$ morphospecies-specific forward and reverse primers, $1 \mu \mathrm{L}$ DNA template and UltraPure water. Cycling conditions according to the Qiagen Multiplex PCR Kit protocol were used with $57{ }^{\circ} \mathrm{C}$ as annealing temperature.

A subset of the post-emergence mummy extracts was also tested with individual morphospecies-specific primer pairs to confirm the multiplex PCR results. This was to control for low DNA yield in post-emergence mummies, especially as the primary parasitoids could have been consumed by hyperparasitoids. All single and 
multiplex PCR reactions included a negative control, without a DNA template, and a positive control, containing an equal mix of all parasitoid species and psyllid DNA.

\section{Cophylogenetic analysis}

Phylogenetic congruence (the degree of match between two phylogenies) may indicate parallel divergence of interacting species, and therefore can reveal patterns of speciation and diversification of species. Phylogenetic congruence was examined between all parasitoid morphospecies and their respective hosts, i.e. between 1) P1 and their psyllid hosts; 2) P2 and their psyllid hosts; 3) the hyperparasitoid, $\mathrm{H}$, and its host (P2), as well as the respective psyllid hosts of $\mathrm{P} 2$; and 4 ) $\mathrm{HH}$ and its hosts (P1 and psyllids). Parasitoid phylogenies were constructed from the dominant genotype (GT) for each morphospecies, or GT1 if there was no dominant genotype (Additional file 1: Table S3). Both host and parasitoid phylogenies were rooted with the most distantly related species according to p-distances. As different approaches exist for cophylogenetic analyses [56], we employed three current methods that have recently also been successfully applied to test codivergence and host switching of bacterial endosymbionts and their psyllid hosts [43]: phylogenetic topology-based TreeMap 3 [57], and the two phylogenetic distance-based methods, ParaFit [58] and Hommola's cospeciation test (hereafter HCT) [59]. Briefly, TreeMap 3 was used to reconstruct tanglegrams and to assess congruence between host and parasitoid phylogenies. Statistical significance was evaluated by mapping 1000 random parasitoid trees onto the host tree to estimate whether the number of codivergence events was due to chance alone. ParaFit and HCT were implemented in R 3.2.2 [60] using the ape 3.3 package [61]. Both of these methods were assessed from patristic distance matrices for the host and parasitoid phylogenies, as well as an association matrix of the host - parasitoid links. The observed correlation between matrices was compared to a null distribution of matrix correlations created through 10,000 permutations.

\section{Results}

\section{Collection and molecular identification of parasitoid morphospecies}

A total of 1023 parasitoid wasps emerged from mummies in gelatine capsules or were collected from zip-lock bags containing nymphs of eight species of Cardiaspina and Spondyliaspis (Table 1). Eight distinct parasitoid morphotypes (with separate female and male morphotypes) belonging to five morphospecies (female and male morphotypes were paired into morphospecies, while for some morphospecies only females were collected) were identified across all psyllid populations. According to existing identification keys and previous extensive population surveys of GB Cardiaspina sp. [35], three morphospecies (P1, $\mathrm{P} 2$ and $\mathrm{HH}$ ) belonged to Psyllaephagus and the other $(\mathrm{H})$ was Coccidoctonus psyllae Riek (Hymenoptera: Encyrtidae). Apart from these four major morphospecies, one additional rare species was found, as females only, from the C. tenuitela and Spondyliaspis sp. populations. The closest 28S rDNA BLAST match for this species was Euryischia sp. (Hymenoptera: Aphelinidae).

The number of wasp individuals sampled varied between five from C. vittaformis to 456 from GB Cardiaspina sp. populations. P1 was the dominant morphospecies in five of the eight Cardiaspina populations, and was present in every Cardiaspina population (Table 1). P2 and $\mathrm{H}$ were found in six Cardiaspina populations, including in a few Cardiaspina populations where they were dominant or common. HH was less abundant, but still present in six Cardiaspina populations.

DNA sequences were obtained for cytb (344 bp) and $28 \mathrm{~S}$ rDNA (509 bp) of all parasitoid morphospecies from each host population (Additional file 1: Table S3), with a few exceptions: only a single P1 individual was obtained from the C. fiscella population and it failed to yield readable sequences; adult specimens of P2 from the C. tenuitela and P1 from the Spondyliaspis sp. populations were not obtained for DNA characterisation, but were detected by PCR in mummies; and the aphelinid only amplified for $28 \mathrm{~S}$ rDNA from the Spondyliaspis sp. host while attempts to amplify $c y t b$ were unsuccessful. Within the concatenated cytb and 28S rDNA phylogeny, the morphospecies of $\mathrm{HH}, \mathrm{H}$ and $\mathrm{P} 2$ all constituted monophyletic clades, while P1 was divided into two paraphyletic clades (Fig. 1).

For cytb, P1 from C. albitextura, C. densitexta, $C$. tenuitela and $C$. vittaformis were $\leq 2.6 \%$ diverged and were deemed to be a single species according to bPTP (Table 2, Fig. 1). P1 from C. maniformis and GB Cardiaspina sp. were highly diverged (13.1\%) from each other and from P1 of the other host species (17.2-18.6\%), and were, according to bPTP, separate species. P2 from $C$. albitextura, $C$. densitexta and GB Cardiaspina sp. were $0.3 \%$ diverged from each other and possibly a single species. P2 from C. fiscella, C. maniformis and Spondyliaspis sp. were more diverged from each other and from the other P2 (8.4-16.3\%), and potentially represented three additional $\mathrm{P} 2$ species. $\mathrm{HH}$ from $C$. albitextura and $C$. tenuitela were $<1 \%$ diverged from each other, but $>15 \%$ diverged from $\mathrm{HH}$ of C. fiscella, C. maniformis, GB Cardiaspina sp. and Spondyliaspis sp., which were $\leq 4.7 \%$ diverged from each other; therefore, $\mathrm{HH}$ potentially formed two species. At $<5 \%$ divergence between all populations, $\mathrm{H}$, according to $\mathrm{bPTP}$, constituted a single species. There was very little divergence between haplotypes within all morphospecies collected from the 
Table 1 Number of parasitoid wasps emerged from mummies isolated in individual gelatine capsules or from nymphs in zip-lock bags, separated by morphotype, sex and host species

\begin{tabular}{|c|c|c|c|c|c|c|c|c|c|}
\hline \multirow[t]{2}{*}{ Host } & \multirow{2}{*}{$\begin{array}{l}\text { P1 (Psyllaephagus sp.) } \\
\text { female }\end{array}$} & \multicolumn{2}{|c|}{ P2 (Psyllaephagus sp.) } & \multicolumn{2}{|c|}{ H (Coccidoctonus psyllae) } & \multicolumn{2}{|c|}{ HH (Psyllaephagus sp.) } & \multirow{2}{*}{$\begin{array}{l}\text { Unknown species } \\
\text { (Aphelinidae) } \\
\text { female }\end{array}$} & \multirow[t]{2}{*}{ Total } \\
\hline & & male & female & male & female & male & female & & \\
\hline C. albitextura & 67 & 2 & 10 & 17 & 50 & 0 & 10 & 0 & 156 \\
\hline C. densitexta & 75 & 2 & 3 & 2 & 2 & 0 & 0 & 0 & 84 \\
\hline C. fiscella & 1 & 2 & 2 & 59 & 60 & 4 & 9 & 0 & 137 \\
\hline C. maniformis & 12 & 29 & 21 & 0 & 0 & 6 & 10 & 0 & 78 \\
\hline C. tenuitela & 53 & 0 & 0 & 6 & 14 & 0 & 8 & 1 & 82 \\
\hline C. vittaformis & 5 & 0 & 0 & 0 & 0 & 0 & 0 & 0 & 5 \\
\hline GB Cardiaspina sp. & 301 & 57 & 27 & 26 & 26 & 10 & 9 & 0 & 456 \\
\hline Spondyliaspis sp. & 0 & 4 & 9 & 3 & 0 & 2 & 5 & 2 & 25 \\
\hline Total & 514 & 96 & 72 & 113 & 152 & 22 & 51 & 3 & 1023 \\
\hline
\end{tabular}

same host population, indicating an absence of cryptic species within host populations.

$28 \mathrm{~S}$ rDNA sequence divergence patterns were similar to $c y t b$ yet smaller; P2, in particular, displayed very little divergence between host populations ( $\leq 2.3 \%$ ) (Additional file 1: Table S7). Putative species delimitation of $28 \mathrm{~S}$ rDNA was the same as for $c y t b$ except that P2 was suggested to be a single species, although with low support (0.57) (Additional file 1: Table S8). Furthermore, the support was generally higher for $c y t b$ species groupings than for $28 \mathrm{~S}$ rDNA.

The psyllid phylogeny separated the seven Cardiaspina species according to the described species, although $C$. densitexta, C. tenuitela and GB Cardiaspina sp. formed one clade that was indicated to constitute a single species by bPTP analysis (Fig. 2).

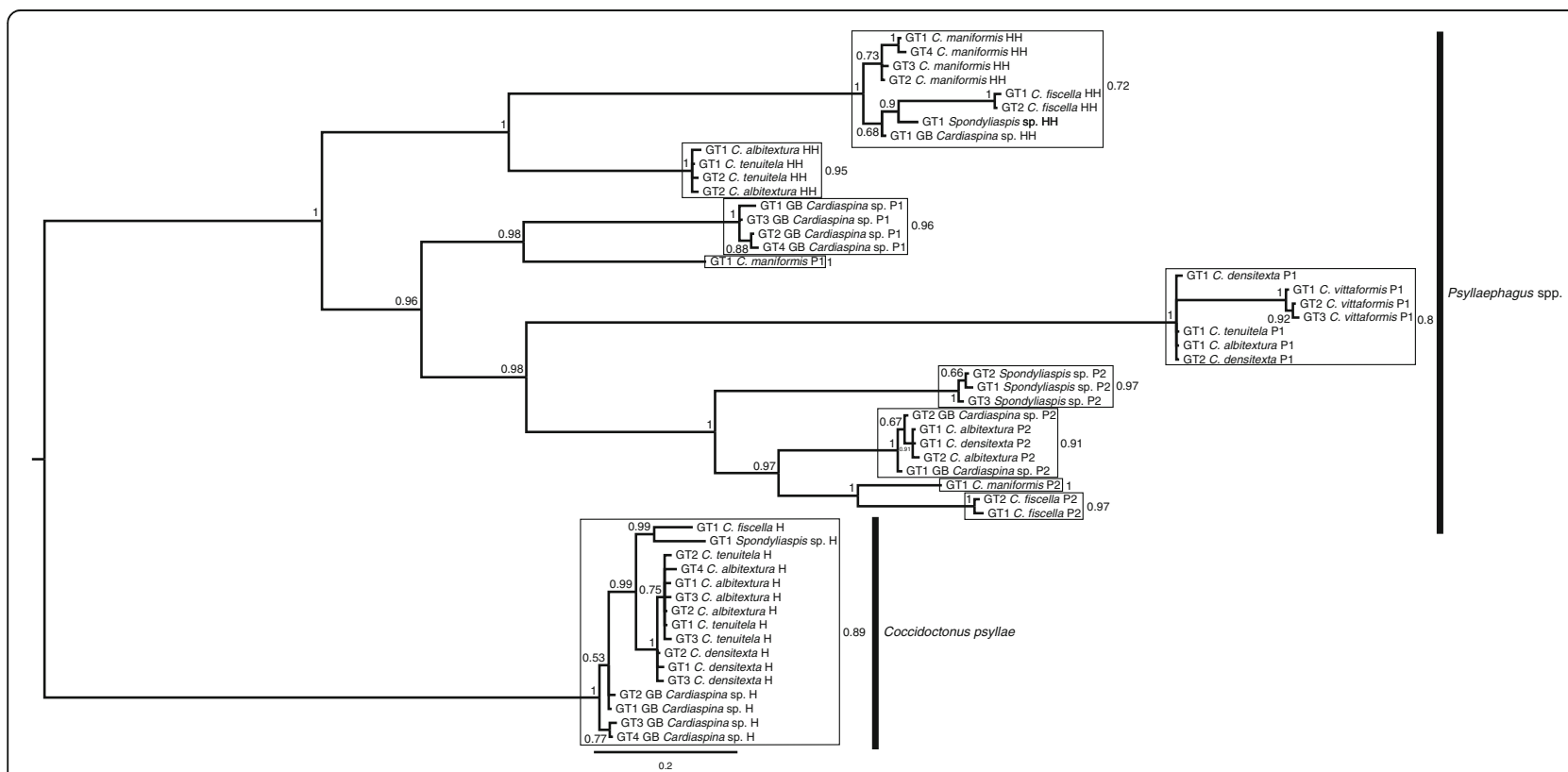

Fig. 1 Majority consensus phylogeny of parasitoid species associated with seven Cardiaspina spp. and one Spondyliaspis sp. host populations. The phylogeny was constructed based on mitochondrial cytb (344 bp) and nuclear $28 \mathrm{~S}$ rDNA (509 bp) using Bayesian inference. The genotype (GT) number, host species name and abbreviation of parasitoid morphospecies are included as tip labels. Abbreviations for parasitoid morphospecies are defined by their trophic roles, i.e. P1 and P2 (primary parasitoids), H (hyperparasitoid) and HH (heteronomous hyperparasitoid). P1, P2 and HH are Psyllaephagus species. The phylogeny was rooted with the $\mathrm{H}$ clade (Coccidoctonus psyllae). Bayesian posterior support values are provided at the nodes, and the scale bar represents the number of substitutions per site. Frames enclose bPTP putative species according to cytb, and the posterior delimitation probabilities are provided outside of the frames 
Table 2 Maximum cytb (344 bp) sequence divergence (\%) comparisons of parasitoid morphospecies (P1, P2, H and HH) between populations of psyllid hosts

\begin{tabular}{|c|c|c|c|c|}
\hline Comparison & P1 & P2 & $\mathrm{H}$ & $\mathrm{HH}$ \\
\hline C. albitextura - C. albitextura & 0 & 0.3 & 0.9 & 0.9 \\
\hline C. albitextura - C. densitexta & 0.3 & 0.3 & 1.2 & - \\
\hline C. albitextura - C. fiscella & - & 10.5 & 2.3 & 17.2 \\
\hline C. albitextura - C. maniformis & 17.4 & 11.6 & - & 15.1 \\
\hline C. albitextura - C. tenuitela & 0 & - & 0.6 & 0.9 \\
\hline C. albitextura - C. vittaformis & 2.3 & - & - & - \\
\hline C. albitextura - GB Cardiaspina sp. & 17.2 & 0.3 & 3.8 & 15.4 \\
\hline C. albitextura - Spondyliaspis sp. & - & 14.8 & 3.5 & 16.9 \\
\hline C. densitexta - C. densitexta & 0.3 & 0 & 0.6 & - \\
\hline C. densitexta - C. fiscella & - & 10.5 & 1.7 & - \\
\hline C. densitexta - C. maniformis & 17.4 & 11.6 & - & - \\
\hline C. densitexta - C. tenuitela & 0.3 & - & 0.9 & - \\
\hline C. densitexta - C. vittaformis & 2.6 & - & - & - \\
\hline C. densitexta - GB Cardiaspina sp. & 17.2 & 0.3 & 3.2 & - \\
\hline C. densitexta - Spondyliaspis sp. & - & 14.8 & 3.5 & - \\
\hline C. fiscella - C. fiscella & - & 0.6 & 0 & 0.6 \\
\hline C. fiscella - C. maniformis & - & 8.4 & - & 4.7 \\
\hline C. fiscella - C. tenuitela & - & - & 2 & 17.4 \\
\hline C. fiscella - C. vittaformis & - & - & - & - \\
\hline C. fiscella - GB Cardiaspina sp. & - & 10.5 & 2 & 2.9 \\
\hline C. fiscella - Spondyliaspis sp. & - & 14.8 & 2.9 & 3.2 \\
\hline C. maniformis - C. maniformis & 0 & 0 & - & 0.6 \\
\hline C. maniformis - C. tenuitela & 17.4 & - & - & 15.7 \\
\hline C. maniformis - C. vittaformis & 18.6 & - & - & - \\
\hline C. maniformis - GB Cardiaspina sp. & 13.1 & 11.6 & - & 1.7 \\
\hline C. maniformis - Spondyliaspis sp. & - & 16.3 & - & 3.2 \\
\hline C. tenuitela - C. tenuitela & 0 & - & 0.6 & 0.3 \\
\hline C. tenuitela - C. vittaformis & 2.3 & - & - & - \\
\hline C. tenuitela - GB Cardiaspina sp. & 17.2 & - & 3.5 & 15.7 \\
\hline C. tenuitela - Spondyliaspis sp. & - & - & 3.2 & 17.2 \\
\hline C. vittaformis - C. vittaformis & 0.6 & - & - & - \\
\hline C. vittaformis - GB Cardiaspina sp. & 18.6 & - & - & - \\
\hline C. vittaformis - Spondyliaspis sp. & - & - & - & - \\
\hline GB Cardiaspina sp. - GB Cardiaspina sp. & 0.9 & 0.3 & 0.9 & 0 \\
\hline GB Cardiaspina sp. - Spondyliaspis sp. & - & 14.8 & 4.9 & 2 \\
\hline Spondyliaspis sp. - Spondyliaspis sp. & - & 0.6 & 0 & 0 \\
\hline
\end{tabular}

\section{Morphological characteristics and trophic interactions of parasitoids}

Four morphospecies emerged from the mummies in gelatine capsules. $\mathrm{H}$ (Co. psyllae) was distinct from the other morphotypes (Psyllaephagus spp.) in the more setose male antennae, longer female ovipositor and lack of metallic green colour. P1 had a metallic green thorax and head, while P2 had a metallic green abdomen, which also differed in shape from P1. For P1 only females were found while the other morphospecies had both females and males, with species characteristic antennae in males. $\mathrm{HH}$ females were indistinguishable from $\mathrm{P} 1$ females but had a distinct genotype that matched the distinctive $\mathrm{HH}$ males; they also emerged from opaque mummies, whereas P1 emerged from translucent mummies.

The morphospecies-specific PCR on post-emergence mummies demonstrated that the function of the major parasitoid morphospecies was highly conserved across host systems (Table 3). Two of the four major morphospecies were primary parasitoids (P1 and $\mathrm{P} 2$ ), one was a hyperparasitoid $(\mathrm{H})$ that attacked $\mathrm{P} 2$, and another was a heteronomous hyperparasitoid $(\mathrm{HH})$ that used psyllids as host for female wasps and P1 as host for male wasps. It was not possible to establish the trophic level of the aphelinid species due to the low sample number. Besides emerged adult wasps from mummies (Table 1), we also found the DNA of P2 in H-hyperparasitised mummies in the C. tenuitela population, and the DNA of P1 in hyperparasitised mummies from which male $\mathrm{HH}$ emerged in the Spondyliaspis sp. population, indicating that these morphospecies were present in these host systems although we did not collect any emerging adult specimens from these host populations. No larval competition between the two primary parasitoid species was detected, because DNA of both P1 and P2 was never detected within the same mummy.

Overall, DNA detection success rate was very high, except for P1 which had a low detection success rate (Table 3). If the hyperparasitoid and psyllid host DNA were successfully detected in hyperparasitised mummies, then the primary parasitoid was also detected on every occasion.

\section{Cophylogenetic analysis}

Phylogenetic congruence between psyllid hosts and P1 was not supported. TreeMap mapped the parasitoid phylogeny onto the host phylogeny and reconciled their evolutionary history through four possible types of evolutionary events: codivergence in host and parasitoid; duplication (divergence in parasitoid but not in host); lineage sorting/loss (divergence in host but not in parasitoid, or loss of parasitoid); host switching. TreeMap found five optimal solutions with a maximum of 6 codivergence events, $1-4$ duplications, $0-10$ lineage sorting/ losses and $0-4$ host switches by mapping P1 onto their psyllid hosts (Fig. 3). A statistical test could not be performed due to the P1 phylogeny not being fully resolved. The distance-based analyses found no congruence between the host and P1 phylogenies (ParaFitGlobal $=0.046$, $P=0.101$, ParaFit; $P=0.196$, HCT $)$. 


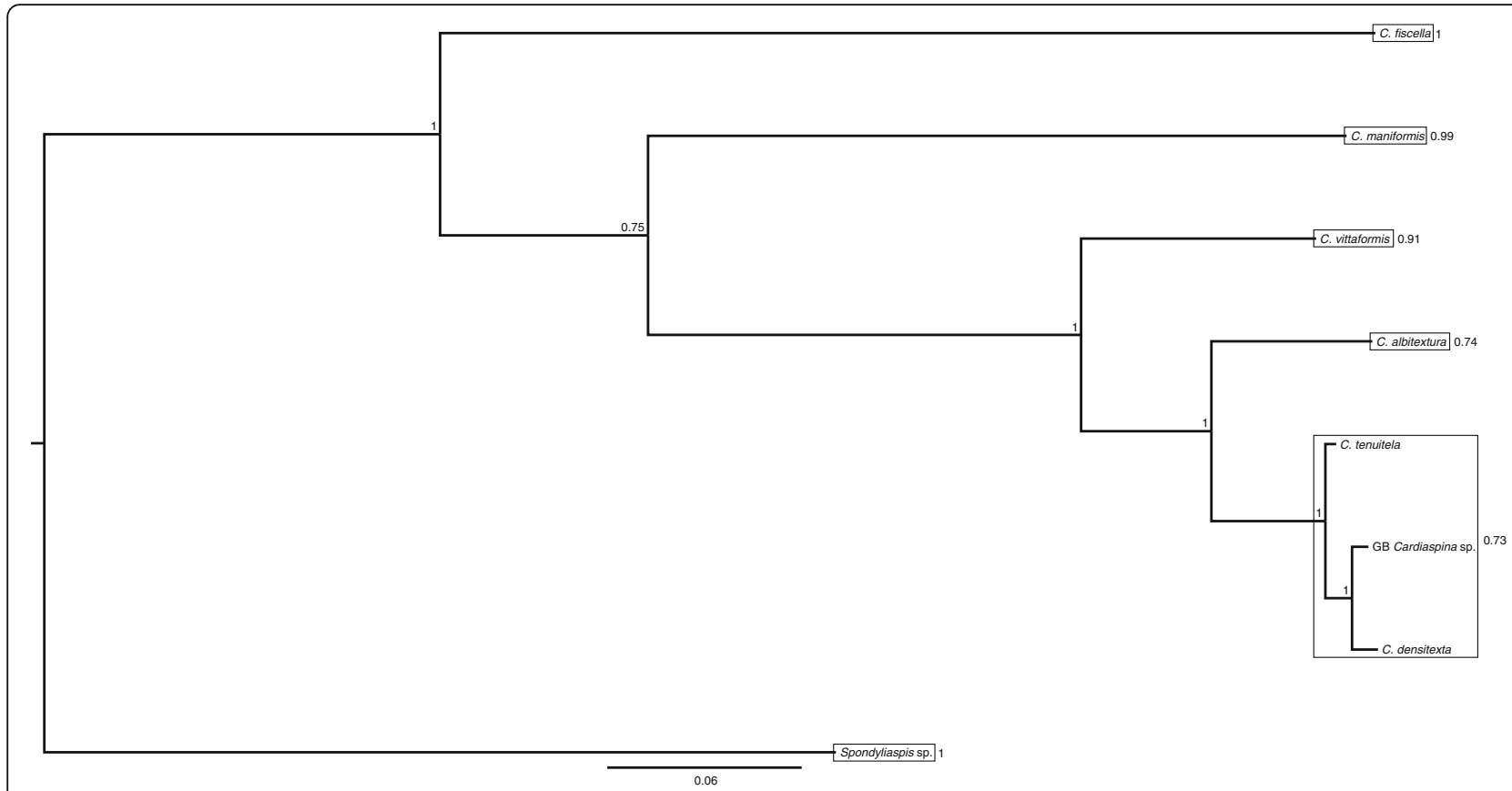

Fig. 2 Majority consensus phylogeny of Cardiaspina and other psyllid species, constructed based on mitochondrial COI (506 bp) and cytb (398 bp), and nuclear wg (268 bp), EF-1 alpha (281 bp) and CAD (323 bp) using Bayesian inference, and Spondyliaspis sp. to root the tree. Bayesian posterior support values are provided at the nodes, and the scale bar represents the number of substitutions per site. Frames enclose bPTP putative species, and the posterior delimitation probabilities are provided outside of the frames

TreeMap did not find phylogenetic congruence for psyllid hosts and P2 $(P=0.73)$ based on just one optimal solution, with 6 codivergence events, 4 duplications, 6 lineage sorting/losses and 0 host switches (Fig. 4). However, both ParaFit (ParaFitGlobal $=0.004, P=0.005$ ) and HCT $(P=0.035)$ supported phylogenetic congruence between psyllid hosts and P2.

Phylogenetic congruence was supported between P2 and $\mathrm{H}$ based on ParaFit (ParaFitGlobal $<0.001, P=0.043$ ), HCT $(P=0.016)$ and TreeMap $(P=0.01)$, which found just one optimal solution, 8 codivergence events and no other types of event (Fig. 5a). Furthermore the psyllids were also congruent with the phylogeny of $\mathrm{H}$ according to ParaFit (ParaFitGlobal $<0.001, P=0.02$ ) and HCT $(P=0.015)$. However, TreeMap did not support phylogenetic congruence $(P=0.755)$, and found two solutions with a maximum of 6 codivergence events, $3-4$ duplications, 7 lineage sorting/losses and $0-1$ host switches (Fig. 5b).

Phylogenetic congruence between $\mathrm{P} 1$ and $\mathrm{HH}$ was supported by ParaFit (ParaFitGlobal $<0.001, P=0.043$ ), and HCT $(P=0.084)$ and TreeMap $(P=0.07)$ were nearly significant. TreeMap found just one optimal solution with 6 codivergence events and no other events (Fig. 6a). The other hosts of $\mathrm{HH}$, the psyllids, were not phylogenetically congruent with $\mathrm{HH}$; ParaFit (ParaFitGlobal $=0.004, P=0.205)$, HCT $(P=0.458)$ and TreeMap $(P=0.116)$, which found seven solutions with a maximum of 8 codivergence events, 2-4 duplications, 1-4 lineage sorting/losses and 0-5 host switches (Fig. 6b).

\section{Discussion}

Our study revealed high genetic diversity in parasitoid communities associated with populations of eight psyllid species feeding on Eucalyptus trees. The populations comprised six recognised and phylogenetically diverse species of the psyllid genus Cardiaspina, as well as GB Cardiaspina sp. and one Spondyliaspis sp., and included significant defoliators of Eucalyptus in Australia and overseas. The sampled psyllid species are specific to one or few Eucalyptus species, and were sampled from either sympatric or geographically distant populations (maximum distance was close to $1400 \mathrm{~km}$ between Sydney and Adelaide). From our sampling we obtained four common parasitoid morphospecies with highly conserved trophic roles; two Psyllaephagus primary parasitoid morphospecies, one Psyllaephagus heteronomous hyperparasitoid morphospecies, and one obligate hyperparasitoid species, Co. psyllae. All three Psyllaephagus morphospecies contained cryptic genetic diversity that could represent up to nine cryptic species. Diversification was characterised by functional conservation of morphospecies (i.e. they were either primary parasitoid, hyperparasitoid or heteronomous hyperparasitoid across all host species), host specificity (to just one or few 
Table 3 Results of morphospecies-specific multiplex PCR screening of post-emergence Cardiaspina and Spondyliaspis mummies

\begin{tabular}{|c|c|c|c|c|c|c|c|}
\hline $\begin{array}{l}\text { Host } \\
\text { species }\end{array}$ & $\begin{array}{l}\text { Emerged } \\
\text { parasitoid species }\end{array}$ & $\begin{array}{l}\text { Emerged } \\
\text { species DNA }\end{array}$ & $\begin{array}{l}\text { Psyllid } \\
\text { DNA }\end{array}$ & $\begin{array}{l}\text { Other } \\
\text { species DNA }\end{array}$ & $\begin{array}{l}\text { Informative } \\
\text { mummies }\end{array}$ & $\begin{array}{l}\text { Uninformative } \\
\text { mummies }\end{array}$ & $\begin{array}{l}\text { Detection } \\
\text { success (\%) }\end{array}$ \\
\hline \multirow[t]{7}{*}{ C. albitextura } & P1 & Yes & Yes & No & 20 & 40 & 33 \\
\hline & P2 female & Yes & Yes & No & 7 & 3 & 70 \\
\hline & P2 male & Yes & Yes & No & 2 & 0 & 100 \\
\hline & $\mathrm{H}$ female & Yes & Yes & P2 & 20 & 5 & 80 \\
\hline & $\mathrm{H}$ male & Yes & Yes & P2 & 15 & 2 & 88 \\
\hline & HH female & Yes & Yes & No & 5 & 5 & 50 \\
\hline & $\mathrm{HH}$ male & - & - & - & - & - & - \\
\hline \multirow[t]{7}{*}{ C. fiscella } & P1 & Yes & Yes & No & 0 & 1 & 0 \\
\hline & P2 female & Yes & Yes & No & 2 & 0 & 100 \\
\hline & P2 male & Yes & Yes & No & 2 & 0 & 100 \\
\hline & $\mathrm{H}$ female & Yes & Yes & P2 & 20 & 7 & 74 \\
\hline & $\mathrm{H}$ male & Yes & Yes & P2 & 20 & 6 & 77 \\
\hline & HH female & Yes & Yes & No & 8 & 1 & 89 \\
\hline & $\mathrm{HH}$ male & Yes & Yes & P1 & 4 & 0 & 100 \\
\hline \multirow[t]{7}{*}{ C. maniformis } & P1 & Yes & Yes & No & 2 & 10 & 17 \\
\hline & P2 female & Yes & Yes & P2 & 17 & 4 & 81 \\
\hline & P2 male & Yes & Yes & P2 & 20 & 3 & 87 \\
\hline & $\mathrm{H}$ female & - & - & - & - & - & - \\
\hline & $\mathrm{H}$ male & - & - & - & - & - & - \\
\hline & HH female & Yes & Yes & No & 8 & 2 & 80 \\
\hline & $\mathrm{HH}$ male & Yes & Yes & P1 & 4 & 2 & 67 \\
\hline \multirow[t]{7}{*}{ C. tenuitela } & P1 & Yes & Yes & No & 8 & 45 & 15 \\
\hline & P2 female & - & - & - & - & - & - \\
\hline & P2 male & - & - & - & - & - & - \\
\hline & $\mathrm{H}$ female & Yes & Yes & P2 & 14 & 0 & 100 \\
\hline & $\mathrm{H}$ male & Yes & Yes & P2 & 4 & 2 & 67 \\
\hline & $\mathrm{HH}$ female & Yes & Yes & No & 5 & 3 & 63 \\
\hline & $\mathrm{HH}$ male & - & - & - & - & - & - \\
\hline \multirow[t]{7}{*}{ GB Cardiaspina sp. } & P1 & Yes & Yes & No & 20 & 162 & 11 \\
\hline & P2 female & Yes & Yes & No & 20 & 5 & 80 \\
\hline & P2 male & Yes & Yes & No & 20 & 4 & 83 \\
\hline & $\mathrm{H}$ female & Yes & Yes & P2 & 20 & 6 & 77 \\
\hline & $\mathrm{H}$ male & Yes & Yes & P2 & 20 & 6 & 77 \\
\hline & HH female & Yes & Yes & No & 8 & 1 & 89 \\
\hline & $\mathrm{HH}$ male & Yes & Yes & P1 & 3 & 7 & 30 \\
\hline \multirow[t]{7}{*}{ Spondyliaspis sp. } & P1 & - & - & - & - & - & - \\
\hline & P2 female & Yes & Yes & No & 3 & 6 & 33 \\
\hline & P2 male & Yes & Yes & No & 4 & 0 & 100 \\
\hline & $\mathrm{H}$ female & - & - & - & - & - & - \\
\hline & $\mathrm{H}$ male & Yes & Yes & P2 & 2 & 1 & 67 \\
\hline & HH female & Yes & Yes & No & 4 & 1 & 80 \\
\hline & $\mathrm{HH}$ male & Yes & Yes & P1 & 2 & 0 & 100 \\
\hline
\end{tabular}

Uninformative mummies were PCR negative for either the psyllid host or the emerging parasitoid. For P1, only a female morphotype was found across all host species. Similarly for $\mathrm{HH}$ of C. albitextura and C. tenuitela, only a female morphotype was found. It was therefore concluded that P1 for all host species and $\mathrm{HH}$ from C. albitextura and C. tenuitela were thelytokous. $\mathrm{HH}$ from C. albitextura and C. tenuitela is likely a cryptic species that is distinct from other $\mathrm{HH}$ morphospecies 


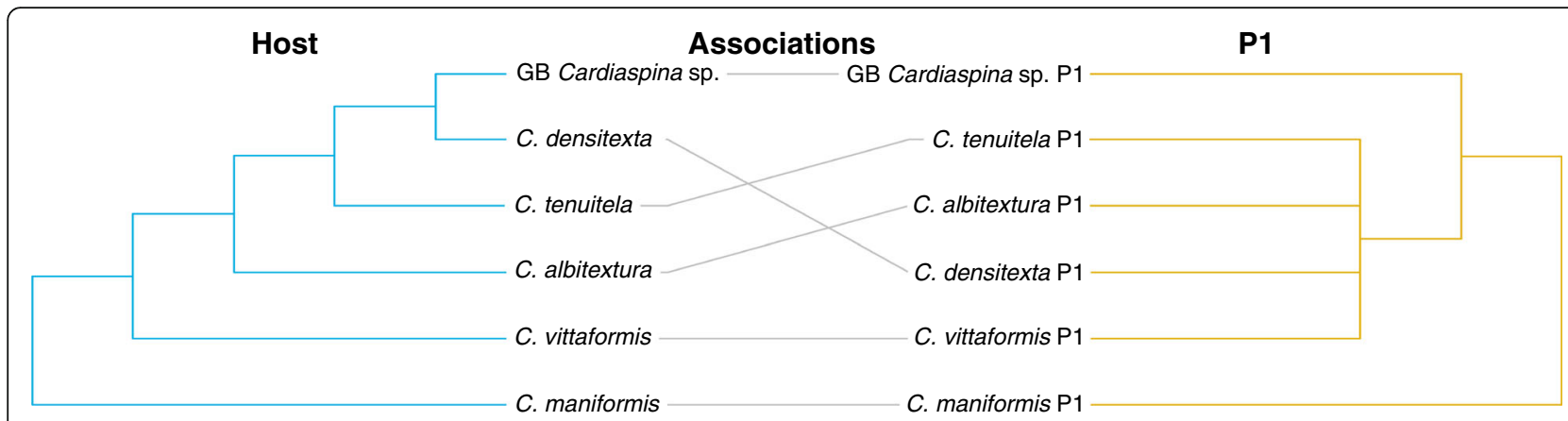

Fig. 3 Tanglegram of concatenated host psyllid COI (506 bp), cytb (398 bp), wg (268 bp), EF-1 alpha (281 bp) and CAD (323 bp), and concatenated primary parasitoid P1 cytb (344 bp) and $28 \mathrm{~S} \mathrm{rDNA} \mathrm{(509} \mathrm{bp)} \mathrm{phylogenies,} \mathrm{listed} \mathrm{by} \mathrm{their} \mathrm{host} \mathrm{associations}$

Cardiaspina species) and ecological niche specificity driven by geographical differentiation and Eucalyptus host tree distribution. These results suggest that even at a low host taxonomic scale, within a host psyllid genus specialised to Eucalyptus and diversified across Eucalyptus species, koinobiont endoparasitoids are highly restricted by their intimate relationships with their host species so that there may be little prospect of finding generalist species. This supports the view that host specialisation is a major factor in parasitoid speciation [3-6], and is also an important conclusion with respect to development of biological control programs for invasive species. Furthermore, by using our DNA-based profiling approach for host-parasitoid interactions we have discovered that one of the Psyllaephagus morphospecies is a heteronomous hyperparasitoid. Until now, heteronomous life histories (i.e. male and female individuals of a parasitoid species use a different host species) have only been described for species in another hymenopteran family (Aphelinidae) and one strepsipteran family (Myrmecolacidae) [62].

\section{Parasitoid morphospecies and trophic roles}

The populations of eight psyllid species sampled across south eastern Australia represented one Spondyliaspis sp., six described Cardiaspina spp. and GB Cardiaspina sp. that has not been assigned to any known species due to its new host tree association [35]. However, DNA characterisation suggested that GB Cardiaspina sp., C. densitexta and C. tenuitela are either a single species or a complex of closely related sibling species [43]. The four major parasitoid morphospecies, consisting of three Psyllaephagus morphospecies and Co. psyllae, were present and abundant in most psyllid populations, including one Psyllaephagus morphospecies (P1) that was present in all psyllid populations.

The morphospecies-specific PCR approach on postemergence mummies revealed highly conserved trophic roles for each morphospecies. Across all the five Cardiaspina and one Spondyliaspis species that we tested with our diagnostic method on post-emergence mummies, two primary parasitoid species, $\mathrm{P} 1$ and $\mathrm{P} 2$, one hyperparasitoid, $\mathrm{H}$, and one heteronomous hyperparasitoid, $\mathrm{HH}$, were detected.

With the exception of $\mathrm{P} 1$, detection of parasitoid DNA in mummies was high $(>60 \%)$. The poor detection success of P1 may be due to its apparent lack of a pupal sheath in the mummy [63], as also seen by the translucent appearance of mummies. Furthermore, in cases of hyperparasitism, DNA of the primary parasitoid host

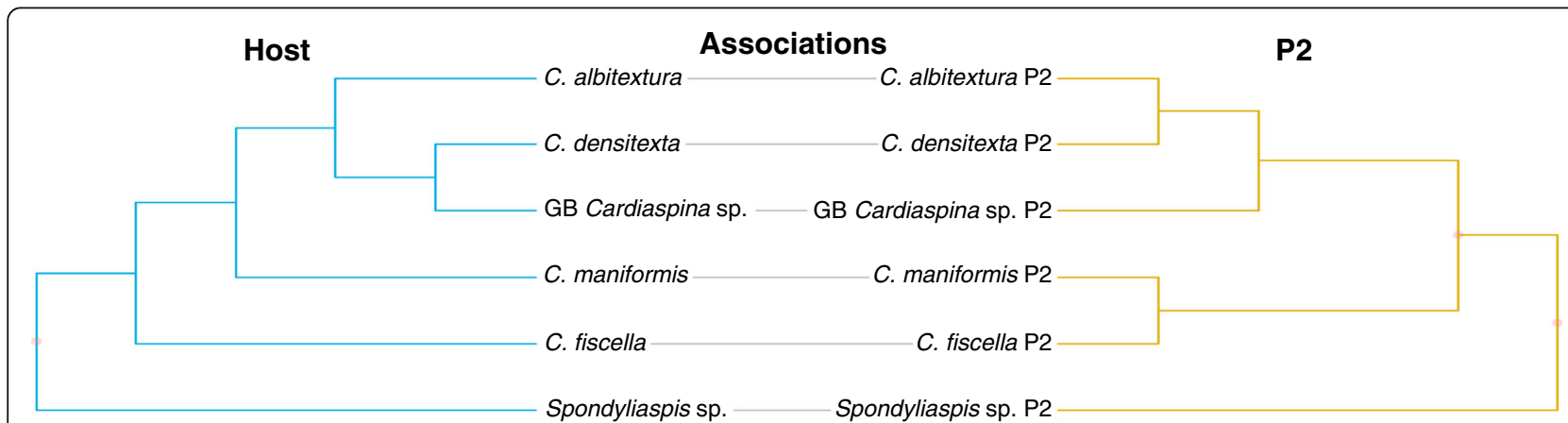

Fig. 4 Tanglegram of concatenated host psyllid COI (506 bp), cytb (398 bp), wg (268 bp), EF-1 alpha (281 bp) and CAD (323 bp), and concatenated primary parasitoid P2 cytb (344 bp) and 28S rDNA (509 bp) phylogenies, listed by their host associations. Dots indicate significance of congruence on individual nodes between host and parasitoid phylogenies 


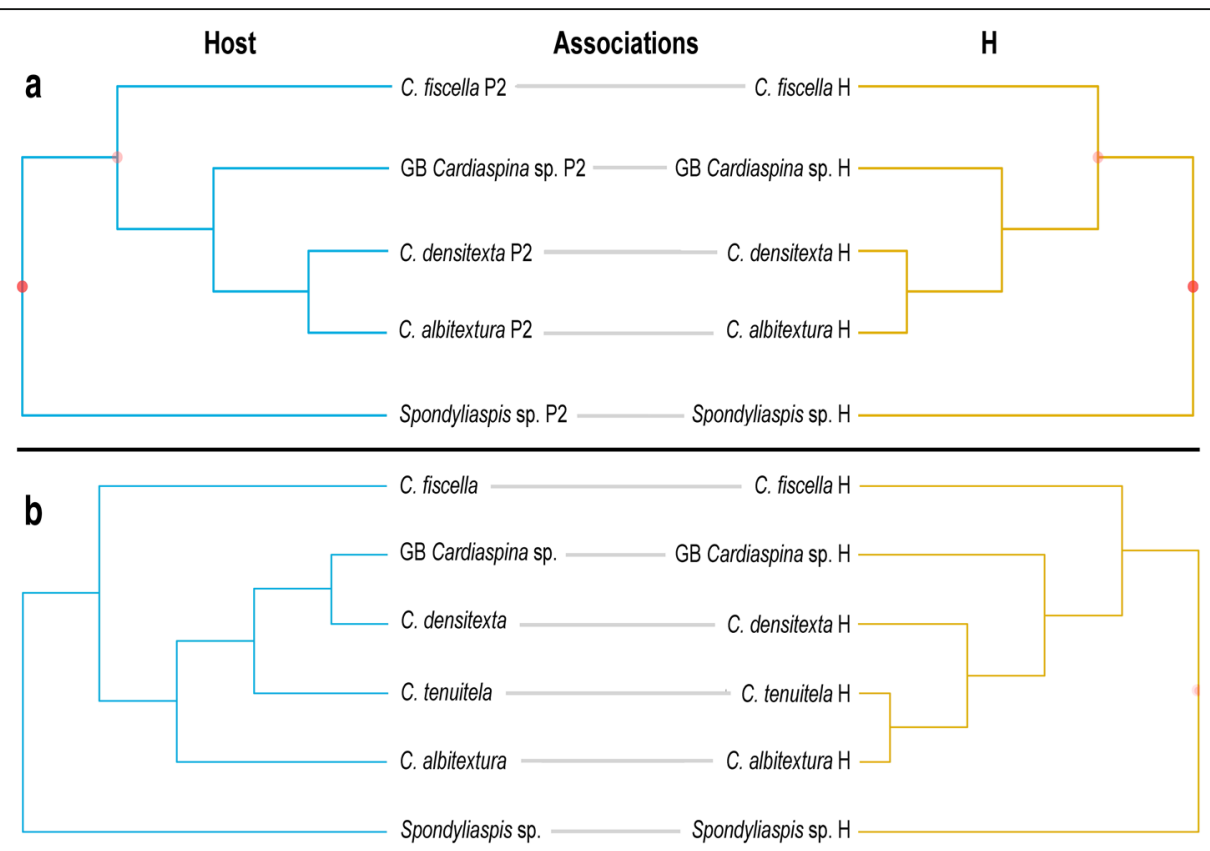

Fig. 5 Tanglegram of (a) concatenated parasitoid P2 (host of H), and concatenated hyperparasitoid H cytb (344 bp) and $28 \mathrm{~S} \mathrm{rDNA} \mathrm{(509} \mathrm{bp)}$ phylogenies, and (b) concatenated host psyllid COI (506 bp), cytb (398 bp), wg (268 bp), EF-1 alpha (281 bp) and CAD (323 bp) and concatenated hyperparasitoid H cytb (344 bp) and $28 \mathrm{~S}$ rDNA (509 bp) phylogenies, listed by their host associations. Dots indicate significance of congruence (darker shade represents higher significance) on individual nodes between host and parasitoid phylogenies

was always detected. We have demonstrated that our approach is very powerful for untangling host - endoparasitoid food webs, including in situations where there is no prior knowledge of any of the species involved. This confirmed theoretical predictions made in a previous study that used molecular diagnostics to detect DNA of a known parasitoid and a known hyperparasitoid species in post-emergence mummies of two aphid species [64]. Furthermore, our approach revealed heteronomous hyperparasitism for only the third time in insects; it has previously been detected in the hymenopteran family Aphelinidae and the strepsipteran family Myrmecolacidae [62]. Therefore this life history strategy may be more common than previously anticipated, but not readily detected due to the cryptic biology of many parasitoid species.

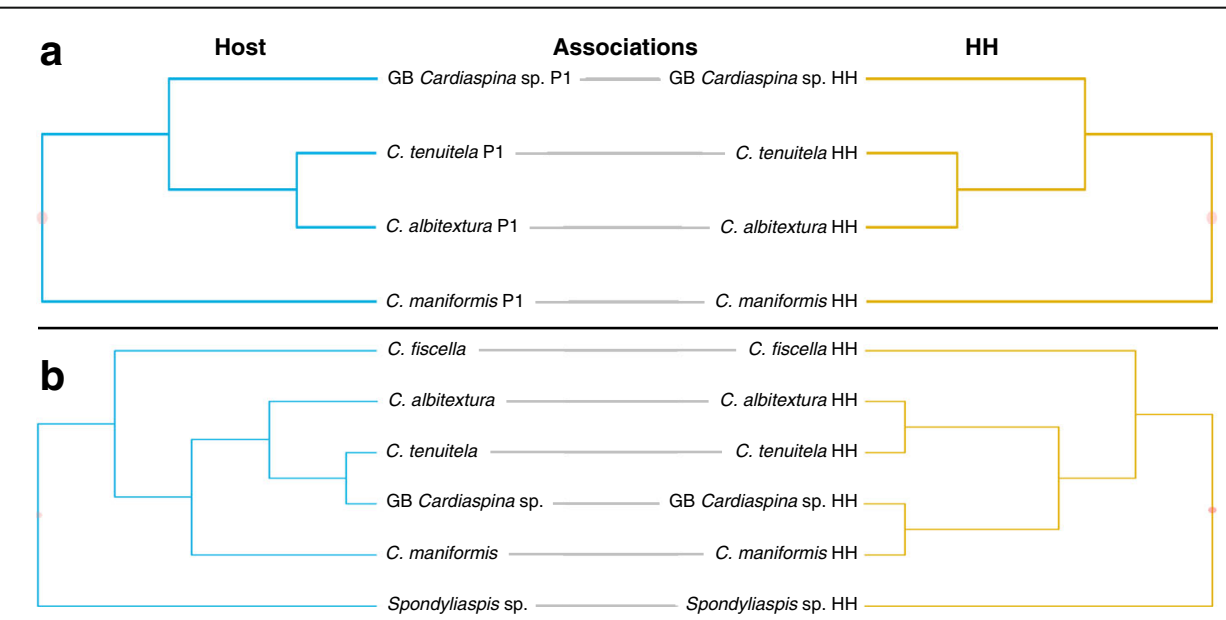

Fig. 6 Tanglegram of (a) concatenated parasitoid P1 and concatenated heteronomous hyperparasitoid HH cytb (344 bp) and $28 \mathrm{~S}$ rDNA (509 bp) phylogenies, and (b) concatenated host psyllid COI (506 bp), cytb (398 bp), wg (268 bp), EF-1 alpha (281 bp) and CAD (323 bp) and concatenated heteronomous hyperparasitoid HH cytb (344 bp) and 28S rDNA (509 bp) phylogenies, listed by their host associations. Dots indicate significance of congruence (darker shade represents higher significance) on individual nodes between host and parasitoid phylogenies 
However, there are also limitations to our multiplex PCR approach; it cannot detect self- or conspecific superparasitisation where the same female, or a female of the same species, parasitises a host that is already parasitised. The design of target-specific primers will be difficult in systems with little genetic divergence between target species.

Our study is so far the best effort to characterise the genetic diversity and interactions within parasitoid communities of psyllids, and of Cardiaspina spp. specifically; P1 was confirmed to be present in populations of all eight host species, and it was the most abundant morphospecies in five. The genus Psyllaephagus is known for its marked sexual dimorphism [28]. P1, however, appeared to have only a female morphotype, thus we concluded that this morphospecies is probably thelytokous. In general, thelytoky appears to confer a fitness advantage over sexual reproduction because of the cost of producing males $[65,66]$. However, it has also been suggested that asexual organisms accumulate deleterious mutations more quickly [67], and this places them at a disadvantage in the coevolutionary arms race with natural enemies [68]. P1 appeared resistant to the obligate hyperparasitoid, $\mathrm{H}$, despite the co-occurrence of $\mathrm{P} 1$ and P2 (supporting high host specificity of $\mathrm{H}$ ); the mechanisms behind this will require further investigation as P1 may prove to be a powerful biological control agent in host species outbreaks outside their native range (furthermore, some P1 species seem less host specific and can parasitise up to four Cardiaspina species). $\mathrm{H}$ appeared absent in the $C$. maniformis population in which P2 was abundant, therefore it is possible that P2 was able to outcompete P1 explaining the shift in this system to P2 as the dominant primary parasitoid. The dominance of $\mathrm{H}$ in the $C$. fiscella population and near complete suppression of its primary parasitoid host P1 could contribute to $C$. fiscella more frequently exhibiting outbreaks [24, 36, 39, 40].

We detected most parasitoid morphospecies even when only a single psyllid population per host species was sampled. However, not all major parasitoid morphospecies were recorded in psyllid populations for which we had a relatively low sampling effort. Irrespective of this, given that we have not detected any morphospecies that are specific to just one psyllid species, we are confident that we have sampled the key parasitoid species of the investigated hosts. Furthermore, while we only sampled one population per psyllid species, this limitation was counterbalanced by wide sampling of phylogenetically diverse representative species of this host genus across distances of about $1400 \mathrm{~km}$ in south eastern Australia, so that overall our study identified the major parasitoid and hyperparasitoid species in this host - parasitoid system across different regions and host species.

\section{Parasitoid cryptic species and diversification}

Without our DNA-based profiling approach and phylogenetic characterisation, the primary parasitoids of Cardiaspina and Spondyliaspis would have appeared to consist of a few generalist morphospecies. However, genetic divergence across host populations of the three Psyllaephagus morphospecies indicated putative cryptic species: P1 could comprise three species (all of which appeared thelytokous); P2 four species, and $\mathrm{HH}$ two species, one from Sydney populations of C. fiscella, C. maniformis, GB Cardiaspina sp. and Spondyliaspis sp. that had both males and females, and a second from Canberra populations of $C$. albitextura and C. tenuitela for which only females were observed. If future research confirms that this second species is thelytokous then it may constitute a heteronomous species that lost its hyperparasitoid male phenotype due to a switch to thelytoky. In contrast to all other parasitoids, $\mathrm{H}$ demonstrated little divergence between populations, and appeared to be a single species. Interestingly, this supported an observation in a pollinating fig wasp - parasitoid system that species with functional roles at higher trophic levels are genetically less diverged than their host [69].

Host specialisation and geographic isolation have recently been reported as the main drivers of diversification, resulting in potential cryptic species in braconid wasps of the subfamily Aphidiinae (Hymenoptera: Braconidae) [21]. Furthermore, the generalist strategy of parasitism has also been challenged by the finding of host-specific cryptic species in tachinid flies [22]. A recent study of Psyllaephagus parasitoids of three Mycopsylla species in Australia also demonstrated a high level of host specificity across their distribution [70]. We therefore conclude host specialisation is a major driver in parasitoid speciation.

All parasitoid morphospecies in our study were either koinobiont endoparasitoids or endohyperparasitoids, which should have greater host specificity because they are constrained by their intimate physiological relationship with their hosts [7]. Diversification processes of P1 were unclear; three putative cryptic species (one per host) were present in three co-occurring Sydney populations of Cardiaspina species (C. maniformis, C. vittaformis and GB Cardiaspina sp.), and the P1 of C. vittaformis from Sydney was shared by populations of $C$. albitextura and C. tenuitela from Canberra and a population of $C$. densitexta from Keith south east of Adelaide. Therefore, phylogenetic congruence analyses did not support codivergence between the P1 morphospecies and its psyllid hosts. TreeMap found evidence of up to four host switch events; however, as the parasitoid phylogeny was not well resolved, it was not possible to determine where these might have occurred. Interestingly, GB Cardiaspina sp. did not share P1 with its closest 
Cardiaspina relatives (C. densitexta in Keith and C. tenuitela in Canberra), while a population of another species from Sydney, C. vittaformis shared P1 with C. densitexta and C. tenuitela.

In contrast, phylogenetic congruence was supported between psyllid hosts and P2 by ParaFit and HCT, although not by TreeMap. A similar result was obtained for Anicetus (Encyrtidae) parasitoids and their scale insect hosts, with the conclusion that diversification was driven by sorting events and high host specificity [10] (as was also found between psyllid hosts and P2). The presence of a number of highly host specific cryptic species rather than a single generalist morphospecies appeared likely for P2: populations of the two closely related host species, $C$. densitexta from Keith and GB Cardiaspina sp. from Sydney shared the same P2. The more diverged C. albitextura from Canberra also shared this P2 genotype, which might be explained by sorting/ loss event, or by a host switch. The cophylogenetic analysis of the P2-specific hyperparasitoid Co. psyllae $(\mathrm{H})$ demonstrated that the shared P2 between $C$. albitextura, C. densitexta and C. tenuitela was the result of a host switch, and this could have occurred as a consequence of the geographic co-occurrence of $C$. albitextura and $C$. tenuitela (albeit we have only detected but not sequenced P2 from C. tenuitela).

We then investigated codivergence between the hyperparasitoid Co. psyllae $(\mathrm{H})$ and both its primary parasitoid host (P2) and the psyllid host of the primary parasitoid. Species delimitation of $c y t b$ suggested that $\mathrm{H}$ was more generalist on several cryptic species of P2. However, $28 \mathrm{~S}$ rDNA was more conserved and suggested a single P2 species, although this was not well supported. Despite being an apparent generalist hyperparasitoid species, $\mathrm{H}$ was codiverging with its multiple P2 host species based on all three tests of phylogenetic congruence, suggesting possible ongoing speciation of $\mathrm{H}$ into host specific species. This is indicative of a long-term association, possibly since its switch from the original host of parasitoids of the genus Coccidoctonus, scale insects [71]. Inclusion of a broader host range of Co. psyllae and phylogenetic analysis including Coccidoctonus species from other hemipteran systems - it also occurs in mealybugs [72] - should provide greater evolutionary resolution of this significant genus of hyperparasitoids.

$\mathrm{HH}$ provided an intriguing opportunity to investigate codivergence of a species with hosts across two trophic levels (herbivore and primary parasitoid). We found that $\mathrm{HH}$ was codiverging with $\mathrm{P} 1$ according to ParaFit, while this was borderline non-significant according to TreeMap and HCT. Sampling from a broader host range may have given a clearer result. However, this trend towards codivergence as a hyperparasitoid of P1 was stronger than its relationship as primary parasitoid with psyllid hosts, for which codivergence was not supported. Host switches of $\mathrm{HH}$ occurred between psyllid populations from the same location; $C$. albitextura and $C$. tenuitela from Canberra, and C. maniformis and GB Cardiaspina sp. from Sydney. $\mathrm{HH}$ diversification appeared more strongly driven by geographic differentiation than host specialisation on psyllids; the $\mathrm{HH}$ from C. albitextura and C. tenuitela from Canberra belonged to the same species and genetically diverged from the $\mathrm{HH}$ species of four psyllid species from Sydney (where it emerged from C. fiscella, C. maniformis, GB Cardiaspina sp. and Spondyliaspis sp.). The weak support for codivergence of $\mathrm{HH}$ with $\mathrm{P} 1$ may have been influenced by the co-occurring Cardiaspina species in Canberra, where they shared $\mathrm{P} 1$ and $\mathrm{HH}$ genotypes.

\section{Conclusions}

Parasitoid communities in Cardiaspina psyllids are dominated by Psyllaephagus spp. and Co. psyllae. There were many cryptic species in Psyllaephagus, and the diversity of this genus may be much higher than currently estimated. Diversification appears to be driven by both host specialisation and host switching between co-occurring hosts. The high host specificity detected for most parasitoid species in this group means that any biological control program will require highly specific parasitoid populations for target psyllids. On the other hand the availability of more generalist parasitoid species may help substitute host specific parasitoids that may not always be available for biological control. From a population dynamic perspective, shared species within parasitoid communities of cooccurring psyllid hosts may also have ecological implications, whereby population fluctuations due to an outbreak of one psyllid species may impact the population dynamics of another psyllid species. The genera Psyllaephagus and Coccidoctonus may be model genera to study host specificity, diversification and speciation, as well as provide insights into the evolution of hyperparasitism, heteronomous hyperparasitism and thelytoky in parasitoids.

\section{Additional file}

Additional file 1: Tables S1 to S8. (DOCX $54 \mathrm{~kb}$ )

\section{Acknowledgements}

We thank Umar Lubanga and Kevin Farnier for their assistance with collection of specimens. Jocelyn King gave advice on the non-destructive DNA extraction protocol. We thank Jennifer Morrow for sharing sequence information for psyllid primer development, John La Salle for confirmation of parasitoid morphospecies and Nicole Fisher for vouchering specimens at ANIC (CSIRO).

\section{Funding}

This research was supported by an Australian Postgraduate Award to AAGH, a research grant of the NSW Government through the Environmental Trust (2012 MG 0003) to MR and JMC, an ARC Future Fellowship to MJS 
(FT100100199) and by the Hawkesbury Institute for the Environment, Western Sydney University.

\section{Availability of data and materials}

Sequence data used in this study have been submitted to GenBank, and accession numbers are provided in the paper.

\section{Authors' contributions}

AAGH and MR designed the project; AAGH, MJS, GST and MR performed field work; AAGH carried out the molecular lab work; AAGH, JMC and MR performed the analyses; $A A G H, M R$ and JMC wrote the manuscript with input from all other authors; all authors approved the final manuscript version.

\section{Competing interests}

The authors declare that they have no competing interests.

\section{Consent for publication}

Not applicable.

\section{Ethics approval and consent to participate}

Not applicable.

\section{Publisher's Note}

Springer Nature remains neutral with regard to jurisdictional claims in published maps and institutional affiliations.

\section{Author details}

${ }^{1}$ Hawkesbury Institute for the Environment, Western Sydney University, Locked Bag 1797, Penrith, NSW 2751, Australia. 'Department of Ecology, Environment \& Evolution, La Trobe University, Melbourne VIC 3086, Australia. ${ }^{3}$ Australian Centre for Evolutionary Biology and Biodiversity, School of Biological Sciences, The University of Adelaide, Adelaide SA 5005, Australia.

\section{Received: 7 February 2017 Accepted: 8 May 2017}

\section{Published online: 06 June 2017}

\section{References}

1. Godfray HCJ. Parasitoids: behavioral and evolutionary ecology. Princeton: Princeton University Press; 1994.

2. LaSalle J, Gauld ID. Parasitic Hymenoptera and the biodiversity crisis. Redia. 1991:74:315-34

3. Stireman JO, Nason JD, Heard SB, Seehawer JM. Cascading host-associated genetic differentiation in parasitoids of phytophagous insects. Proc R Soc B-Biol Sci. 2006;273:523-30

4. Forbes AA, Powell THQ, Stelinski LL, Smith JJ, Feder JL. Sequential sympatric speciation across trophic levels. Science. 2009;323:776-9.

5. Hood GR, Forbes AA, Powell THQ, Egan SP, Hamerlinck G, Smith JJ, Feder JL, Sequential divergence and the multiplicative origin of community diversity. Proc Natl Acad Sci U S A. 2015;112:E5980-9.

6. Condon MA, Scheffer SJ, Lewis ML, Wharton R, Adams DC, Forbes AA. Lethal interactions between parasites and prey increase niche diversity in a tropical community. Science. 2014;343:1240-4

7. Askew RR, Shaw MR. Parasitoid communities: their size, structure and development. In: Waage J, Greathead D, editors. Insect Parasitoids. London: Academic Press; 1986. p. 225-64.

8. Strand MR, Obrycki JJ. Host specificity of insect parasitoids and predators. Bioscience. 1996:46:422-9.

9. Bailey R, Schönrogge K, Cook JM, Melika G, Csóka G, Thuróczy C, Stone GN. Host niches and defensive extended phenotypes structure parasitoid wasp communities. PLoS Biol. 2009:7:e1000179.

10. Deng J, Yu F, Li H-B, Gebiola M, Desdevises Y, Wu S-A, Zhang Y-Z. Cophylogenetic relationships between Anicetus parasitoids (Hymenoptera: Encyrtidae) and their scale insect hosts (Hemiptera: Coccidae). BMC Evol Biol. 2013;13:275.

11. Peralta G, Frost CM, Didham RK, Varsani A, Tylianakis JM. Phylogenetic diversity and co-evolutionary signals among trophic levels change across a habitat edge. J Anim Ecol. 2015;84:364-72

12. Lopez-Vaamonde C, Godfray HCJ, West SA, Hansson C, Cook JM. The evolution of host use and unusual reproductive strategies in Achrysocharoides parasitoid wasps. J Evol Biol. 2005;18:1029-41.
13. Lopez-Vaamonde C, Rasplus JY, Weiblen GD, Cook JM. Molecular phylogenies of fig wasps: partial cocladogenesis of pollinators and parasites. Mol Phylogenet Evol. 2001;21:55-71.

14. Hamerlinck G, Hulbert D, Hood GR, Smith JJ, Forbes AA. Histories of host shifts and cospeciation among free-living parasitoids of Rhagoletis flies. J Evol Biol. 2016;29:1766-79.

15. Völkl W, Starý P. Parasitation of Uroleucon species (Hom., Aphididae) on thistles (Compositae, Cardueae). J Appl Entomol. 1988;106:500-6.

16. Evenhuis HH. Studies on Cynipidae, Alloxystinae. 5. Alloxysta citripes (Thomson) and Alloxysta ligustri n. Sp., with remarks on host specifity in the subfamily. Entomol Ber Amsterdam. 1976;36:140-4.

17. Godfray HCJ, Lewis OT, Memmott J. Studying insect diversity in the tropics. Philos Trans R Soc B Sci. 1999:354:1811-24.

18. Gariepy TD, Kuhlmann U, Gillott C, Erlandson M. Parasitoids, predators and PCR: the use of diagnostic molecular markers in biological control of arthropods. J Appl Entomol. 2007;131:225-40.

19. Smith MA, Eveleigh ES, McCann KS, Merilo MT, McCarthy PC, Van Rooyen KI. Barcoding a quantified food web: crypsis, concepts, ecology and hypotheses. PLoS One. 2011;6:e14424.

20. Hrček J, Godfray HCJ. What do molecular methods bring to host-parasitoid food webs? Trends Parasitol. 2015:31:30-5.

21. Derocles SAP, Plantegenest M, Rasplus JY, Marie A, Evans DM, Lunt DH, Le Ralec A. Are generalist Aphidiinae (Hym. Braconidae) mostly cryptic species complexes? Syst Entomol. 2015;41:379-91.

22. Smith MA, Wood DM, Janzen DH, Hallwachs W, Hebert PDN. DNA barcodes affirm that 16 species of apparently generalist tropical parasitoid flies (Diptera, Tachinidae) are not all generalists. Proc Natl Acad Sci U S A. 2007;104:4967-72.

23. Hollis D. Australian Psylloidea jumping plantlice and lerp insects. Canberra, Australia: Australian Biological Resources Study; 2004.

24. Collett N. Biology and control of psyllids, and the possible causes for defoliation of Eucalyptus camaldulensis Dehnh. (river red gum) in southeastern Australia-a review. Aust For. 2001:64:88-95.

25. Valente C, Manta A, Vaz A. First record of the Australian psyllid Ctenarytaina spatulata Taylor (Homoptera: Psyllidae) in Europe. J Appl Entomol. 2004; 128:369-70.

26. Brennan EB, Gill RJ, Hrusa GF, Weinbaum SA. First record of Glycaspis brimblecombei (Moore) (Homoptera: Psyllidae) in North America: initia observations and predator associations of a potentially serious new pest of eucalyptus in California. Pan Pac Entomol. 1999;75:55-7.

27. de Queiroz Santana DL, Burckhardt D. Introduced Eucalyptus psyllids in Brazil. J For Res. 2007;12:337-44.

28. Riek EF. The Australian species of Psyllaephagus (Hymenoptera: Encyrtidae), parasites of psyllids (Homoptera). Aust J Zool. 1962;10:684-757.

29. Noyes JS, Hanson P. Encyrtidae (Hymenoptera: Chalcidoidea) of Costa Rica: the genera and species associated with jumping plant-lice (Homoptera: Psylloidea). Bull Nat Hist Mus Entomol Ser. 1996;65:105-64.

30. Noyes JS, Hayat M. A review of the genera of indo-Pacific Encyrtidae (Hymenoptera: Chalcidoidea). Bulletin of the British museum (natural history). Entomol Ser. 1984;48:131-395.

31. Steinbauer MJ, Sinai KMJ, Anderson A, Taylor GS, Horton BM. Trophic cascades in bell miner-associated dieback forests: quantifying relationships between leaf quality, psyllids and Psyllaephagus parasitoids. Austral Ecol. 2015;40:77-89.

32. Daane KM, Sime KR, Paine TD. Climate and the effectiveness of Psyllaephagus bliteus as a parasitoid of the red gum lerp psyllid. Biocontrol Sci Tech. 2012:22:1305-20.

33. Berry JA. Key to the New Zealand species of Psyllaephagus Ashmead (Hymenoptera: Encyrtidae) with descriptions of three new species and a new record of the psyllid hyperparasitoid Coccidoctonus psyllae Riek (Hymenoptera: Encyrtidae). Aust J Entomol. 2007:46:99-105.

34. Steinbauer MJ, Burns AE, Hall A, Riegler M, Taylor GS. Nutritional enhancement of leaves by a psyllid through senescence-like processes: insect manipulation or plant defence? Oecologia. 2014;176:1061-74.

35. Hall AAG, Gherlenda AN, Hasegawa S, Johnson SN, Cook JM, Riegler M. Anatomy of an outbreak: the biology and population dynamics of a Cardiaspina psyllid species in an endangered woodland ecosystem. Agric For Entomol. 2015;17:292-301.

36. Campbell KG. The biology and population ecology of two species of Cardiaspina (Hemiptera: Psyllidae) in plague numbers on Eucalyptus grandis in new South Wales. Proc Linnean Soc NSW. 1992;113:135-50.

37. Clark LR. The general biology of Cardiaspina albitextura (Psyllidae) and its abundance in relation to weather and parasitism. Aust J Zool. 1962;10:537-86. 
38. White TCR. Some aspects of the life history, host selection, dispersal and ovipostion of adult Cardiaspina densitexta (Homoptera: Psyllidae). Aust J Zool. 1970;18:105-17.

39. Gherlenda AN, Esveld JL, Hall AAG, Duursma RA, Riegler M. Boom and bust: rapid feedback responses between insect outbreak dynamics and canopy leaf area impacted by rainfall and $\mathrm{CO}_{2}$. Glob Chang Biol. 2016;22:3632-41.

40. Withers TM. Colonization of eucalypts in New Zealand by Australian insects. Austral Ecol. 2001;26:467-76.

41. Australian Government Department of Agriculture. Norfolk Island quarantine survey 2012-2014. p. 2014

42. Flores-Rentería L, Rymer PD, Riegler M. Unpacking boxes: integration of molecular, morphological and ecological approaches reveals extensive patterns of reticulate evolution in box eucalypts. Mol Phylogenet Evol. 2017;108:70-87.

43. Hall AAG, Morrow JL, Fromont C, Steinbauer MJ, Taylor GS, Johnson SN, Cook JM, Riegler M. Codivergence of the primary bacterial endosymbiont of psyllids versus host switches and replacement of their secondary bacterial endosymbionts. Environ Microbiol. 2016;18:2591-603.

44. Riek EF. A new species of Echthroplexis, an encyrtid hyperparasite of lerpforming psyllids on eucalypts (Hymenoptera, Chalcidoidea). Proc Linnean Soc NSW. 1962;87:189-90.

45. King JE, Riegler M, Thomas RG, Spooner-Hart RN. Phylogenetic placement of Australian carrion beetles (Coleoptera: Silphidae). Austral Entomol. 2015; 54:366-75.

46. Gillespie JJ, Munro JB, Heraty JM, Yoder MJ, Owen AK, Carmichael AE. A secondary structural model of the 28S rRNA expansion segments D2 and D3 for chalcidoid wasps (Hymenoptera: Chalcidoidea). Mol Biol Evol. 2005; 22:1593-608.

47. Larkin M, Blackshields G, Brown N, Chenna R, McGettigan PA, McWilliam H, Valentin F, Wallace IM, Wilm A, Lopez R. Clustal W and Clustal X version 2.0. Bioinformatics. 2007:23:2947-8.

48. Tamura K, Stecher G, Peterson D, Filipski A, Kumar S. MEGA6: molecular evolutionary genetics analysis version 6.0. Mol Biol Evol. 2013;30:2725-9.

49. Ronquist F, Teslenko M, van der Mark P, Ayres DL, Darling A, Höhna S, Larget B, Liu L, Suchard MA, Huelsenbeck JP. MrBayes 3.2: efficient Bayesian phylogenetic inference and model choice across a large model space. Syst Biol. 2012:61:539-42

50. Rambaut A: FigTree 1.4.0. http://tree.bio.ed.ac.uk/software/figtree/. Accessed 5 Dec 2012

51. Zhang J, Kapli P, Pavlidis P, Stamatakis A. A general species delimitation method with applications to phylogenetic placements. Bioinformatics. 2013; 29:2869-76.

52. Simon C, Frati F, Beckenbach A, Crespi B, Liu H, Flook P. Evolution, weighting, and phylogenetic utility of mitochondrial gene sequences and a compilation of conserved polymerase chain reaction primers. Ann Entomol Soc Am. 1994:87:651-701.

53. Jermiin LS, Crozier RH. The cytochrome $b$ region in the mitochondrial DNA of the ant Tetraponera rufoniger: sequence divergence in Hymenoptera may be associated with nucleotide content. J Mol Evol. 1994;38:282-94.

54. Corl A, Ellegren H. Sampling strategies for species trees: the effects on phylogenetic inference of the number of genes, number of individuals, and whether loci are mitochondrial, sex-linked, or autosomal. Mol Phylogenet Evol. 2013;67:358-66

55. Villard P, Malausa T. SP-designer: a user-friendly program for designing species-specific primer pairs from DNA sequence alignments. Mol Ecol Resour. 2013;13:755-8.

56. de Vienne DM, Refrégier G, López-Villavicencio M, Tellier A, Hood ME, Giraud T. Cospeciation vs host-shift speciation: methods for testing, evidence from natural associations and relation to coevolution. New Phytol. 2013;198:347-85.

57. Charleston MA, Robertson DL. Preferential host switching by primate lentiviruses can account for phylogenetic similarity with the primate phylogeny. Syst Biol. 2002;51:528-35.

58. Legendre P, Desdevises Y, Bazin E. A statistical test for host-parasite coevolution. Syst Biol. 2002;51:217-34

59. Hommola K, Smith JE, Qiu Y, Gilks WR. A permutation test of host-parasite cospeciation. Mol Biol Evol. 2009;26:1457-68.

60. R Development Core Team. R: A language and environment for statistical computing. Vienna, Austria: R Foundation for Statistical Computing; 2015.

61. Paradis E, Claude J, Strimmer K. APE: analyses of phylogenetics and evolution in R language. Bioinformatics. 2004;20:289-90.

62. Hunter MS, Woolley JB. Evolution and behavioral ecology of heteronomous aphelinid parasitoids. Annu Rev Entomol. 2001;46:251-90.
63. Sullivan DJ, Daane KM, Sime KR, Andrews JW. Protective mechanisms for pupae of Psyllaephagus bliteus Riek (Hymenoptera: Encyrtidae), a parasitoid of the red-gum lerp psyllid, Glycaspis brimblecombei Moore (Hemiptera: Psylloidea). Aust J Entomol. 2006:45:101-5.

64. Varennes Y-D, Boyer S, Wratten SD. Un-nesting DNA Russian dolls-the potential for constructing food webs using residual DNA in empty aphid mummies. Mol Ecol. 2014;23:3925-33.

65. Smith JM. The evolution of sex. Cambridge, UK: Cambridge University Press; 1978

66. Stouthamer R. The use of sexual versus asexual wasps in biological control. BioControl. 1993;38:3-6.

67. Muller HJ. The relation of recombination to mutational advance. Mut Res/ Fundam Mol Mech Mutagen. 1964;1:2-9.

68. Lively CM. A review of red queen models for the persistence of obligate sexual reproduction. J Hered. 2010;101:S13-20.

69. Sutton $T L$, Riegler M, Cook JM. One step ahead: a parasitoid disperses farther and forms a wider geographic population than its fig wasp host. Mol Ecol. 2016:25:882-94.

70. Fromont C, DeGabriel JL, Riegler M, Cook JM. Diversity and specificity of sap-feeding herbivores and their parasitoids on Australian fig trees. Insect Conservation Div. 2016:10:107-19.

71. Ben-Dov Y, Hodgson CJ. Soft scale insects: their biology, natural enemies and control, volume 7B. Amsterdam, Netherlands: Elsevier Science Publishers; 1997

72. Goolsby JA, Kirk AA, Meyerdirk DE. Seasonal phenology and natural enemies of Maconellicoccus hirsutus (Hemiptera: Pseudococcidae) in Australia. Fla Entomol. 2002;85:494-8.

\section{Submit your next manuscript to BioMed Central and we will help you at every step:}

- We accept pre-submission inquiries

- Our selector tool helps you to find the most relevant journal

- We provide round the clock customer support

- Convenient online submission

- Thorough peer review

- Inclusion in PubMed and all major indexing services

- Maximum visibility for your research

Submit your manuscript at www.biomedcentral.com/submit
) Biomed Central 